\title{
Hybrid stenting with silicone $Y$ stents and metallic stents in the management of severe malignant airway stenosis and fistulas
}

\author{
Yu Chen ${ }^{1 \#}$, Zi-Qing Zhou ${ }^{1 \#}$, Jia-Xin Feng ${ }^{1 \#}$, Zhu-Quan Su ${ }^{1 \#}$, Chang-Hao Zhong ${ }^{1}$, Li-Ya Lu ${ }^{1}$, \\ Xiao-Bo Chen ${ }^{1}$, Chun-Li Tang ${ }^{1}$, Subba R. Digumarthy ${ }^{2}$, Alfonso Fiorelli ${ }^{3}$, Ehsan Natour ${ }^{4,5}$, \\ Filippo Lococo $^{6}$, Francesco Petrella ${ }^{7,8}$, Kassem Harris ${ }^{9}$, Takeo Nakada ${ }^{10}$, Nan-Shan Zhong ${ }^{1}$, Shi-Yue Li ${ }^{1}$ \\ ${ }^{1}$ State Key Laboratory of Respiratory Disease, National Clinical Research Center for Respiratory Disease, Guangzhou Institute of Respiratory Health, \\ First Affiliated Hospital of Guangzhou Medical University, Guangzhou, China; ${ }^{2}$ Department of Radiology, Massachusetts General Hospital, Boston, \\ MA, USA; ${ }^{3}$ Thoracic Surgery Unit, Universitàdella Campania Luigi Vanvitelli, Naples, Italy; ${ }^{4}$ University Medical Center of RWTH-Aachen, Aachen, \\ Germany; ${ }^{5}$ University Medical Center Maastricht, Department of Cardiothoracic Surgery, Maastricht, The Netherlands; ${ }^{6}$ Department of Thoracic \\ Surgery, Fondazione Policlinico Universitario “A. Gemelli”, IRCCS, Università Cattolica del Sacro Cuore, Rome, Italy; ${ }^{7}$ Division of Thoracic Surgery, \\ IRCCS European Institute of Oncology, Milan, Italy; ${ }^{8}$ Department of Oncology and Hemato-oncology, University of Milan, Milan, Italy; ${ }^{9}$ Department \\ of Medicine, Division of Pulmonary Critical Care, Interventional Pulmonology Section, Westchester Medical Center, New York Medical College, \\ Valhalla, NY, USA; ${ }^{10}$ Department of Surgery, Division of Thoracic Surgery, The Jikei University School of Medicine, Tokyo, Japan \\ Contributions: (I) Conception and design: SY Li, NS Zhong, Y Chen, ZQ Zhou, JX Feng, ZQ Su; (II) Administrative support: SY Li, NS Zhong, Y \\ Chen; (III) Provision of study materials or patients: SY Li, NS Zhong, Y Chen, ZQ Zhou, JX Feng, ZQ Su, CH Zhong, XB Chen, CL Tang, LY \\ Lu; (IV) Collection and assembly of data: Y Chen, ZQ Zhou, JX Feng, ZQ Su ; (V) Data analysis and interpretation: ZQ Zhou, JX Feng, QS Zhu; \\ (VI) Manuscript writing: All authors; (VII) Final approval of manuscript: All authors. \\ \#These authors contributed equally to this work. \\ Correspondence to: Prof. Shi-Yue Li, MD; Prof. Nan-Shan Zhong, MD. State Key Laboratory of Respiratory Disease, National Clinical Research \\ Center for Respiratory Disease, Guangzhou Institute of Respiratory Health, First Affiliated Hospital of Guangzhou Medical University, 151 Yanjiang \\ Road, Guangzhou 520120, China. Email: lishiyue@188.com; nanshan@vip.163.com.
}

Background: Airway stenting is frequently used in the palliative treatment of patients with advanced tumor-induced airway stenosis and fistulas. However, there is paucity of studies regarding the use of airway stents in restoring patency. The aim of the study was to assess the efficacy and safety of hybrid silicon Y stents and covered self-expanding metal stents (SEMS) and in reestablishing patency in airway stenoses and fistulas.

Methods: This retrospective study included 31 patients between January 2016 to December 2019 with inoperable complex malignant airway stenoses and fistulas, managed with Silicone Y stents, and covered SEMS. The clinical details, clinical outcomes and complications up to 6 months were extracted from medical records. The improvement of performance was assessed based on modified British Medical Research Council (mMRC) dyspnea scores ( $t=6.892, \mathrm{P}<0.001)$, Karnofsky Performance Scores (KPS) $(t=-11.653, \mathrm{P}<0.001)$, and performance status (PS) $(t=3.503, \mathrm{P}<0.001)$.

Result: A total of 31 silicon Y stents and 35 covered SEMSs were inserted. Of the 31 patients (M:F 20:11; age: $54.64 \pm 9.57), 25 / 31(80.6 \%)$ experienced immediate relief of symptoms following stent placement. Patients' mMRC dyspnea scores, KPS, and PS showed significant improvement following stenting. The mean duration of stent placement was $146.3 \pm 47.7$ days, and 17/31 (55\%) patients were alive at 6 months. No major complications related to hybrid stenting were observed during the follow-up period.

Conclusions: Hybrid stenting is a feasible and safe palliative treatment for malignant airway stenosis and fistulas to improve quality of life and can be performed without major complications.

Keywords: Silicone Y stents; self-expending metallic stents; esophageal cancer; lung cancer; airway stenosis; fistula

Submitted Sep 24, 2020. Accepted for publication May 21, 2021.

doi: $10.21037 /$ tlcr-21-353

View this article at: http://dx.doi.org/10.21037/tlcr-21-353 


\section{Introduction}

Malignant airway stenoses and airway-esophageal fistulas are serious complications of tumor growth and treatment in Lung, airway and esophageal, cancers. Malignant airway stenosis occurs frequently in patients with primary lung cancer and in patients with pulmonary metastases from other malignancies, including breast, colon, and renal cell cancer, and estimated to occur in approximately 20-30\% of patients with primary lung cancer (REF). Malignant airway-oesophageal fistulas can form due to both primary tumor progression and secondary to tumor therapy (e.g., radiation or chemotherapy). It has been reported that $77 \%$ of the airway-oesophageal fistulas were caused by primary oesophageal cancer and $16 \%$ by primary lung cancer. With the incidence from oesophageal cancer was $4.3-4.8 \%$ and from primary lung cancer was $0.3 \%$. The symptoms related to these complications include dyspnea, stridor, aspiration and recurrent infections and result in significant impairment to quality of life (1). These complications when seen in in patients who are not candidates for surgery or definitive cancer treatment, require minimally invasive palliative treatment for symptom relief to maintain the patency of airways and cover the fistula (2-4).

Airway stenting is the commonly used option to treat airway stenosis and tracheoesophageal fistulas (4-6) and also as a bridge to tumor-specific treatment (7). The stenosis related to tumors of the carina, lower trachea, and main bronchi and for as tracheobronchial-esophageal fistulas, $\mathrm{Y}$ stents are often used due to configure to the $\mathrm{Y}$ shaped anatomy of the trachea and main bronchi. However, these studies focused on patients with simple stenoses that could be covered by a single stent. There is limited data with regards to the use of stents in management of complex lesions, such as long segment stenoses or airway stenoses combined with fistulas. In this study, we explored the efficacy and safety of hybrid stenting with silicon Y stents and covered self-expanding metal stents (SEMS) in the treatment of complicated malignant airway stenosis and fistulas. We present the following article in accordance with the STROBE reporting checklist (available at http://dx.doi. org/10.21037/tlcr-21-353).

\section{Methods}

\section{Patients}

We retrospectively analyzed the medical data of patients with advanced lung cancer that underwent hybrid stenting between January 2016 to December 2019 at the First Affiliated Hospital of Guangzhou Medical University. A total of 31 patients who underwent hybrid stenting were enrolled in the study. The inclusion criterion was as follows: (I) patients with inoperable advanced malignant stenosis and/ or fistulas; (II) patients with airways narrowed to more than $50 \%$ of the inner luminal diameter resulting in significant dyspnea and post-obstructive atelectasis, and pneumonia; (III) patients with stenosis of the carina involving trachea and one or both main bronchi, or associated fistulas; and (IV) patients with large fistulas near the carina. Our study exclusion criteria included the following: (I) patients with simple stenoses and/or fistulas that could be covered by a single stent; and (II) patients with early-stage cancer for which surgery was an option.

This study was approved by the Ethics Committee of the First Affiliated Hospital of Guangzhou Medical University (Approval Number: 2018-16). All procedures performed in this study involving human participants were in accordance with the Declaration of Helsinki (as revised in 2013). Individual consent for this retrospective analysis was waived.

\section{Surgical procedure}

Treatment strategies were decided by three experienced pulmonologists. Three-dimensional computed tomography (CT) reconstruction and flexible bronchoscopy were performed to evaluate the condition of the patients' airways, including length of stenosis, size of the fistula the condition of adjacent structures, and the luminal diameter. Dilatating balloons (CRE, Boston Scientific, USA) were used to determine the inner luminal diameter following dilation, when required. The size and length of the inserted stents was determined by airway diameter and lesion length. The diameters of the tracheal body and bronchial limbs of the stents were calculated based on 3D-CT imaging of the lower trachea and main bronchi.

Silicone Y stents (Dumon, Novatech, France) were implanted to reestablish the patency at the carina. Stent length was determined by lesion length. Each limb of the $\mathrm{Y}$ stents extended $10 \mathrm{~mm}$ beyond the edge of the lesion. If the distance between the main carina and the most distal point of the lesion in the main bronchi was longer than $20 \mathrm{~mm}$, the limb was set to $10-20 \mathrm{~mm}$ and a covered SEMS (Ultraflex, Boston Scientific, USA) was inserted to overlay the bronchial limb of the $\mathrm{Y}$ stent. The diameter of the covered SEMS matched the inner diameter of the $\mathrm{Y}$ stent, and the length of the covered SEMS matched the length of 
the left and right main bronchi.

All the stents were inserted through rigid bronchoscopy (Storze, Germany) under general anesthesia. Both highfrequency ventilation and conventional mechanical ventilation were used during the procedure. Intraluminal lesions were appropriately resected using holmium laser (VersaPluse PowerSuite, Lumenis, USA), Nd:YAG laser (MY100C, Ligenesis, China), electrosurgical unit (VIO200D, Erbe, Germany), and balloon dilation to recanalize the airways. $\mathrm{Y}$ stents were then placed through the rigid bronchoscope channel using pushing or pullingback techniques. In cases where the patients had fistulas, we used the pulling-back technique so that the distal end of the rigid bronchoscope passed over the fistula. Both bronchial limbs were inserted into the bronchi and then grasped with forceps, the stent gently pulled back until the shorter of the two bronchial limbs slipped into position. Forceps and balloon dilation were then used to gently reposition the stent until it was flush against the main carina and fully covered the lesion (4). If required, SEMS was then inserted using a guidewire and then adjusted using forceps and balloon dilation.

\section{Evaluation of bybrid stent efficacy and safety}

Patients were endoscopically examined after stent implantation on days $1,7,30$, and 180 to check the position and patency of the stent. Symptoms related to stent placement, such as expectoration difficulty, coughing, and shortness of breath, were recorded. Chest radiographs were obtained and determine the location of stent and for complications such as pneumomediastinum. pneumothorax and pneumonia.

The modified British Medical Research Council (mMRC) dyspnea scale was used to assess pulmonary function before and after stent implantation (3). Quality of life was assessed by Eastern Cooperative Oncology Group performance status (PS) and Karnofsky Performance Score (KPS) both before and after stenting.

\section{Statistical analysis}

Statistical analysis was performed using SPSS 16.0 (SPSS Inc., Chicago, IL, USA). All patient characteristics were analyzed using the Kolmogorov-Smirnov test. Normally distributed numerical data were presented as mean \pm standard deviation (SD), and other numerical data were presented as median (interquartile range). Paired $t$-tests were used to assess differences between paired data. Independent $t$-tests were used to assess differences between groups. Differences of $\mathrm{P}<0.05$ were considered statistically significant.

\section{Results}

\section{Patient characteristics}

A total of 31 patients with locally advanced or metastatic lung cancer (clinical stage III or IV) and severe central airway stenosis at carina were enrolled in this study, 9 patients also had concomitant tracheoesophageal fistula. The mean age of patients were 54.64 \pm 9.57 , with a prevalence of male (35.5\%). All patients had tumor invasion or compression of the main carina, with or without involvement of the lower trachea or main bronchi. All the 31 patients received a silicone $\mathrm{Y}$ stent to restore patency at carina, and in addition 35 SEMSs were implanted to reestablish the patency of main bronchi (19 in Right main bronchus and 16 in left main bronchus). Before stenting, 23 out of 31 (74\%) patients received palliative treatments including chemoradiotherapy alone $(n=4)$ and chemoradiotherapy plus radiation therapy $(n=19)$. The clinical characteristic of the 31 enrolled patients is summarized in Table 1.

\section{Clinical outcomes}

The mean duration of the procedure was $91.1 \pm 33.8$ minutes. A successful restore of airway patency was obtained after stent insertion in all cases, an example was reported in Figure 1 and Figure 2. Of the 31 patients, 25 experienced immediate relief of dyspnea after stenting. Of the 9 patients with concomitant fistulas, 5 were able to eat without coughing or aspirating after the stenting procedure, while the 4 other patients required indwelling gastric tubes. Pulmonary infections were controlled within 7-9 days in all patients.

A significant improvement in $\mathrm{mMRC}$ scores $(3.5 \pm 0.51$ vs. $2.87 \pm 0.50 ; \mathrm{P}<0.05)$ and in KPS scores $(45.81 \pm 15.22$ vs. $61.93 \pm 9.80 ; \mathrm{P}<0.05)$ were observed after the procedure. No significant improvement was observed in PS score before and after procedure $(2.67 \pm 0.65$ vs. $2.58 \pm 0.56$; $\mathrm{P}=0.0325)$ in all patients. However, if considered only patients with a PS value more than $3(n=18)$, stent insertion was associated with a significant improvement of PS value. The improvement of mMRC, KPS, and PS after stenting are shown in Table 2. 
Table 1 Baseline patient characteristics

\begin{tabular}{|c|c|c|c|c|c|}
\hline Patient no. & Age in years/sex & Primary tumor & Stage & $\begin{array}{l}\text { Previous } \\
\text { tumor-specific therapy }\end{array}$ & $\begin{array}{l}\text { Post-stenting } \\
\text { tumor-specific therapy }\end{array}$ \\
\hline 1 & 78/female & Squamous lung cancer & T3N1M0 (III A) & CRT & RT \\
\hline 2 & $67 /$ male & Esophageal squamous cancer & T4N3M0 (IV A) & CRT, RT & - \\
\hline 3 & $50 /$ male & Squamous lung cancer & T4N2M0 (III B) & CRT, RT & CRT, RT \\
\hline 6 & 49/female & Small cell lung cancer & T4N2M1a (IV A) & CRT, RT & - \\
\hline 7 & $56 /$ male & Esophageal squamous cancer & T3N2M1a (IV A) & CRT, RT & CRT, RT \\
\hline 8 & $68 /$ male & Esophageal squamous cancer & T3N2M1a (IV A) & CRT, RT & - \\
\hline 12 & 54/male & Esophageal squamous cancer & T4N2M1c (IV B) & CRT, RT & CRT, RT \\
\hline 13 & $50 /$ female & Squamous lung cancer & T4N2M1a (IV A) & CRT, RT & CRT, RT \\
\hline 14 & 47/male & Esophageal squamous cancer & T4N2M1c (IV B) & CRT, RT & CRT, RT \\
\hline 15 & 45/female & Squamous lung cancer & T4N2M1a (IV A) & CRT, RT & - \\
\hline 16 & 46/male & Esophageal squamous cancer & T4N2M1b (IV A) & CRT, RT & - \\
\hline 17 & $56 /$ female & $\begin{array}{l}\text { Pulmonary lymphoepithelioma-like } \\
\text { carcinoma }\end{array}$ & T4N2M1c (IV B) & CRT, RT & CRT, RT \\
\hline 23 & 66/female & Squamous lung cancer & T4N2M1a (IV A) & CRT, RT, TT & CRT, RT \\
\hline 24 & 48/male & Lung adenocarcinoma & T4N3M1a (IV A) & CRT, RT, TT & CRT, TT \\
\hline 25 & 47/male & Squamous lung cancer & T4N3M0 (III C) & CRT, RT & CRT, RT \\
\hline 26 & $54 /$ male & Squamous lung cancer & T4N3M0 (III C) & CRT & RT \\
\hline 27 & 54/male & Squamous lung cancer & T3N2M1a (IV A) & - & CRT, RT \\
\hline 28 & $67 /$ male & Lung adenocarcinoma & T2bN2M1a (IV A) & CRT, RT & $\pi$ \\
\hline 29 & $60 /$ male & Squamous lung cancer & T4N3M0 (III C) & CRT & - \\
\hline 30 & $55 /$ female & Squamous lung cancer & T3N2M1c (IV B) & - & CRT, RT \\
\hline 31 & $65 /$ female & Squamous lung cancer & T4N3M0 (III C) & CRT, RT & - \\
\hline
\end{tabular}

CRT, chemoradiotherapy; RT, radiation therapy; TT, targeted therapy. 

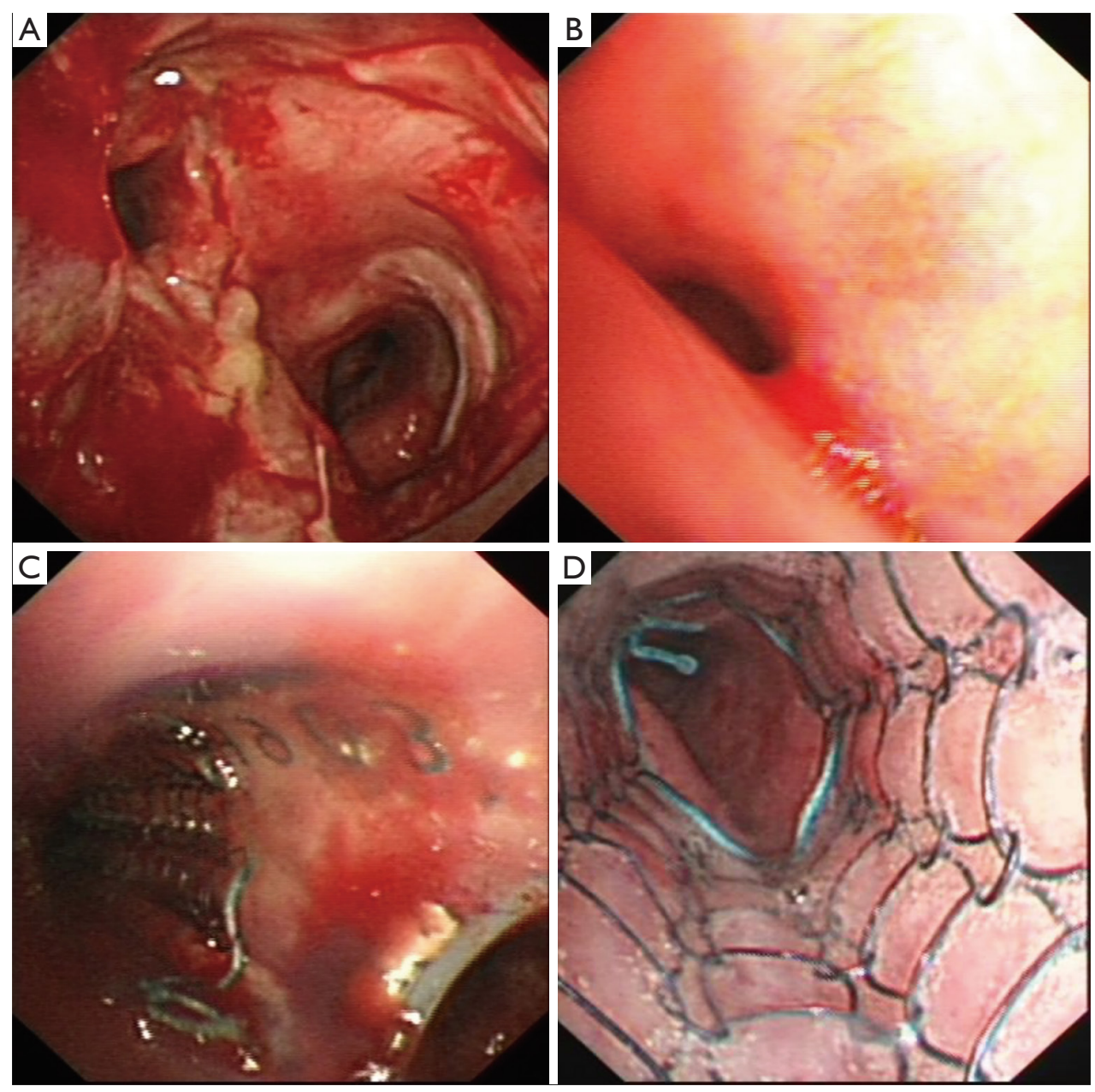

Figure 1 Bronchoscopy images of main carina and left main bronchus tumor involvement before and after hybrid stent insertion. (A) Main carina involvement; (B) left main bronchus compression; (C) join of silicone Y stent and covered SEMS; (D) distal end of covered SEMS. SEMS, self-expanding metal stents
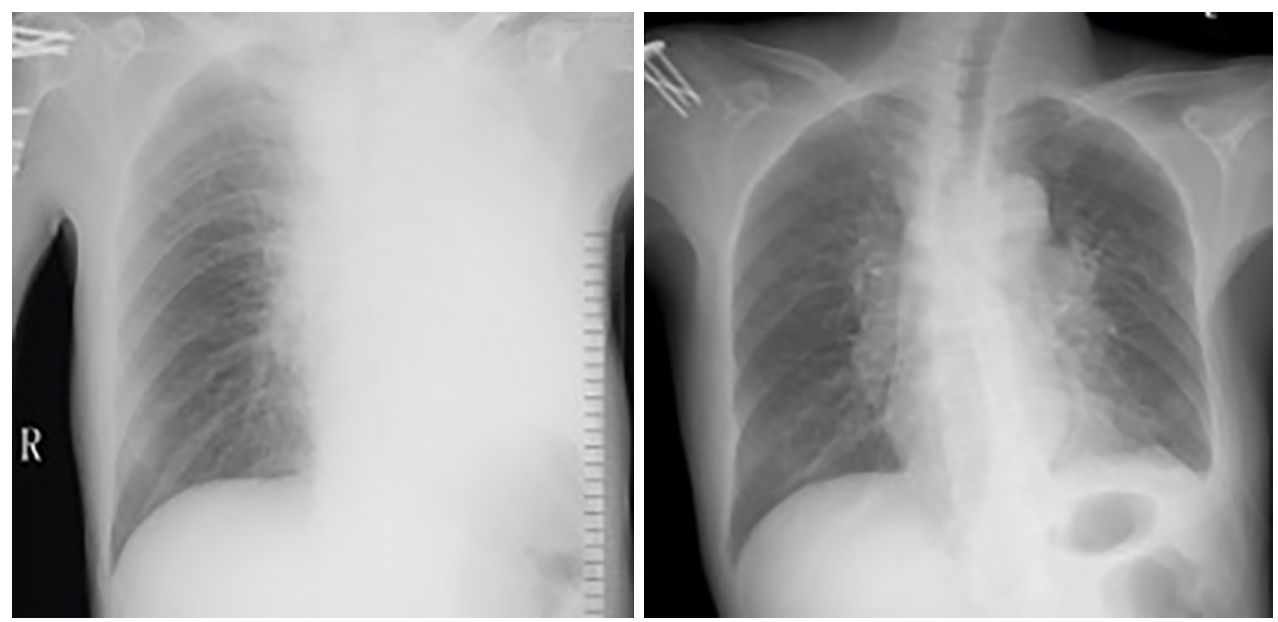

Figure 2 Chest radiography before and after hybrid stenting. Left: airway obstruction-induced left lung atelectasis; right; hybrid stenting reestablished the airway and the left lung was recruited. 
Table 2 Changes in $\mathrm{mMRC}$, KPS, and PS after stenting

\begin{tabular}{|c|c|c|c|c|c|}
\hline Tumor relative score & Before stenting & After stenting & $\mathrm{n}$ & $t$ & $\mathrm{P}$ \\
\hline KPS & $45.81 \pm 15.22$ & $61.93 \pm 9.80$ & 31 & -11.653 & $<0.001$ \\
\hline PS (All patients) & $2.67 \pm 0.65$ & $2.58 \pm 0.56$ & 31 & 1.000 & 0.325 \\
\hline PS (Patients with PS $\geq 3$ ) & $2.00 \pm 0.00$ & $2.23 \pm 0.44$ & 13 & -1.897 & 0.082 \\
\hline
\end{tabular}

mMRC, Modified British Medical Research Council dyspnea scale; KPS, Karnofsky Performance Score; PS, Eastern Cooperative Oncology Group performance status.

\section{Follow-up}

The mean duration of stent placement was $146.3 \pm 47.7$ days. In growth of granulation tissue was observed in 4 cases within 60 days, however, the granulation did not affect stent patency and was easily removed by rigid bronchoscopy. Secretion retention was observed in 9 patients following stenting and resolved with bronchoscopic aspiration. No stent migration of either silicone Y stents or SEMSs occurred. In one patient, SEMS was removed after 151 days due to recanalization of the fistula and a cardiac septal defect occluder was placed to occlude the fistula. In one patient, $\mathrm{Y}$ stent was replaced with another 2 months later due to tumor grow.

Sixteen out of 31 patients (51.6\%) were still alive 6 months after stent implantation while the other 15 patients had died of their underlying disease. The outcomes of stent placement are shown in Table 3.

\section{Complications}

No complications related to stent insertion as bleeding, pneumothorax, or mediastinal emphysema, were seen during and after the procedure. Ingrowth of granulation tissue was observed in 4 cases within 60 days; however, the granulation did not affect stent patency and was easily removed. Secretion retention was observed in 9 patients following stenting. But no stents-related respiratory infections happened. No stent migration of either silicone Y stents or SEMSs occurred during the follow-up period and there were no deaths attributed to stent-related complications.

\section{Discussion}

While covered SEMSs and silicon stents have been widely used in the management of airway stenosis and fistulas, to our knowledge, our study is one of few that explored the use of hybrid stents in the management of these challenging conditions. There was immediate relief of symptoms and improvement in mMRC scores, KPS, and PS scores after placement of hybrid stents. Our study demonstrates that hybrid stents employing both silicone stents and SEMS are safe and effective in treatment for malignant tracheal and bronchial stenoses and fistulas. Severe airway stenosis and fistula formation are rare but encountered in primary and metastatic tumors of the airways and as a complication of treatment with chemotherapy and radiotherapy. Stenting of the airways is a widely accepted method for treating these conditions. Two types of SEMS are available: covered SEMS and non-covered SEMS. Non-covered SEMSs are rarely used due to the risk of removal related severe complications. Also, non-covered SEMSs could not be used in sealing the fistula. The most commonly used SEMSs in China are Ultraflex stents and Nanjing Eco stents. Several studies regarding the use of these SEMS confirm the efficacy of them in reestablishing the stenotic airway or sealing the fistulas (REF). In case of main carinal obstruction of fistula involving main carinal, lower tracheal or proximal main bronchus, metallic or silicone Y-shaped stents are necessary (8). Y-shaped stents consist of a tracheal body and 2 bronchial limbs that imitate the anatomy of the carina. The silicone $\mathrm{Y}$ stents have greater radial strength and cause less irritation to the mucosa compared to metallic Y-shaped stents, and are associated with a lower risk of migration and airway injury $(9,10)$. Also, these stents are easy to remove after tumor-specific therapies $(4,10)$. In general, Silicon Y stents are well tolerated for long periods, especially in patients with airway obstructions or fistulas involving the lower trachea, main carina, and proximal main bronchi $(1,4)$. A previous study by Dutau et al. demonstrated that Dumon Y stents were effective and well-tolerated when used for treating stenoses of the trachea and main 
Table 3 Silicone Y stent and SEMS placement data

\begin{tabular}{|c|c|c|c|c|c|c|c|c|}
\hline No. & Fistula & $\begin{array}{l}\text { Location } \\
\text { (area of fistula in } \mathrm{cm}^{2} \text { ) }\end{array}$ & $\begin{array}{l}\text { Pre-stenting } \\
\text { intervention }\end{array}$ & Type of Y stent* & $\begin{array}{l}\text { Type of } \\
\text { SEMS in } \\
\text { right main } \\
\text { bronchus }{ }^{\star \star}\end{array}$ & $\begin{array}{l}\text { Type of } \\
\text { SEMS in } \\
\text { left main } \\
\text { bronchus }\end{array}$ & $\begin{array}{l}\text { Duration } \\
\text { (d) }\end{array}$ & Outcome (d) \\
\hline 1 & & $\begin{array}{l}\text { Trachea, main carina, } \\
\text { and right main } \\
\text { bronchus }\end{array}$ & $\begin{array}{l}\text { Laser resection; } \\
\text { balloon dilation }\end{array}$ & $110-15-30 / 18-14-14$ & $10-20$ & - & $>180$ & $\begin{array}{l}\text { Alive with stents } \\
(>180)\end{array}$ \\
\hline 3 & & $\begin{array}{l}\text { Trachea, main carina, } \\
\text { and left main bronchus }\end{array}$ & $\begin{array}{l}\text { Laser resection; } \\
\text { balloon dilation }\end{array}$ & $60-20-10 / 16-13-13$ & - & $12-40$ & $>180$ & $\begin{array}{l}\text { Alive with stents } \\
(>180)\end{array}$ \\
\hline 6 & & $\begin{array}{l}\text { Main carina and both } \\
\text { main bronchi }\end{array}$ & $\begin{array}{l}\text { APC; balloon } \\
\text { dilation }\end{array}$ & $40-25-15 / 15-12-12$ & $12-30$ & $12-40$ & 164 & Died \\
\hline 7 & + & Lower trachea $(0.5 \times 0.5)$ & $\begin{array}{l}\text { Laser resection; } \\
\text { balloon dilation }\end{array}$ & $55-15-10 / 18-14-14$ & $12-30$ & - & $>180$ & $\begin{array}{l}\text { Alive with stents } \\
(>180)\end{array}$ \\
\hline 8 & + & $\begin{array}{l}\text { Lower trachea and right } \\
\text { main bronchus }(2.5 \times 1)\end{array}$ & $\begin{array}{l}\text { Laser resection; } \\
\text { balloon dilation }\end{array}$ & $50-25-30 / 18-14-14$ & $14-40$ & - & 92 & Died \\
\hline 9 & & $\begin{array}{l}\text { Trachea and both main } \\
\text { bronchi }\end{array}$ & $\begin{array}{l}\text { APC; balloon } \\
\text { dilation }\end{array}$ & $75-15-15 / 15-12-12$ & $12-40$ & - & 93 & Died \\
\hline 12 & + & Lower trachea $(1 \times 0.5)$ & $\begin{array}{l}\text { Laser resection; } \\
\text { balloon dilation }\end{array}$ & $50-15-30 / 16-13-13$ & $14-40$ & - & $>180$ & $\begin{array}{l}\text { Alive with stents } \\
(>180)\end{array}$ \\
\hline 13 & & $\begin{array}{l}\text { Trachea, main carina, } \\
\text { and both main bronchi }\end{array}$ & $\begin{array}{l}\text { Electrocautery; } \\
\text { balloon dilation }\end{array}$ & $85-15-15 / 15-13-13$ & $12-30$ & - & $>180$ & $\begin{array}{l}\text { Alive with stents } \\
(>180)\end{array}$ \\
\hline 14 & + & $\begin{array}{l}\text { Lower trachea and left } \\
\text { main bronchus }(3 \times 1.5)\end{array}$ & $\begin{array}{l}\text { APC; balloon } \\
\text { dilation }\end{array}$ & $45-10-15 / 16-13-13$ & - & $10-40$ & $>180$ & $\begin{array}{l}\text { Alive with stents } \\
(>180)\end{array}$ \\
\hline 15 & & $\begin{array}{l}\text { Trachea and left main } \\
\text { bronchus }\end{array}$ & $\begin{array}{l}\text { Laser resection; } \\
\text { balloon dilation }\end{array}$ & $55-15-30 / 15-12-12$ & - & $12-40$ & 95 & Died \\
\hline 16 & + & $\begin{array}{l}\text { Lower trachea and left } \\
\text { main bronchus }(1 \times 1)\end{array}$ & $\begin{array}{l}\text { Laser resection; } \\
\text { balloon dilation }\end{array}$ & $45-10-30 / 16-13-13$ & - & $14-40$ & 7 & Lost \\
\hline 17 & & $\begin{array}{l}\text { Trachea, main carina, } \\
\text { and left main bronchus }\end{array}$ & $\begin{array}{l}\text { Laser resection; } \\
\text { balloon dilation }\end{array}$ & $60-10-15 / 16-13-13$ & - & $12-30$ & $>180$ & $\begin{array}{l}\text { Alive with stents } \\
(>180)\end{array}$ \\
\hline 18 & + & Lower trachea $(2 \times 2.5)$ & $\begin{array}{l}\text { Laser resection; } \\
\text { balloon dilation }\end{array}$ & $50-15-35 / 18-14-14$ & $14-40$ & - & 91 & Died \\
\hline
\end{tabular}

Table 3 (continued) 
Table 3 (continued)

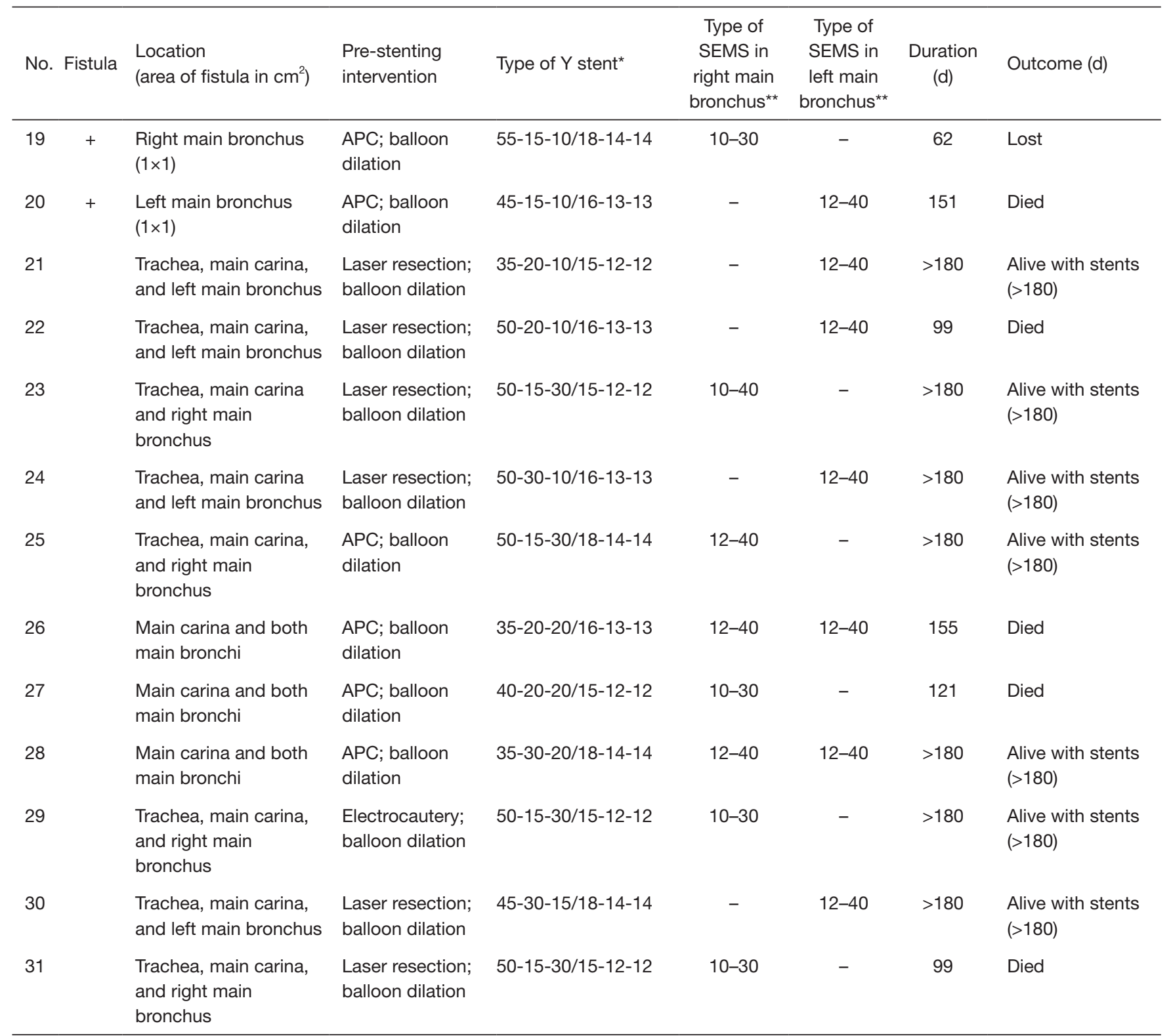

${ }^{*}$, Y stent types are presented as length of tracheal body-left limb-right limb/diameter of tracheal body-left limb-right limb; ${ }^{* *}$, metal stent types are presented as diameter.

stem bronchi and airway esophageal fistula, but this study included only a few patients with involvement of carina (4).

Thus, we proposed a new method, not been reported before, as the insertion of two different stents including $\mathrm{Y}$ and SEMS. The rationale of our strategy was that $\mathrm{Y}$ stent assured ventilation of central airway as lower trachea, carina and main bronchi, while the SEMS, deployed over the distal end of $\mathrm{Y}$ stent, restored patency of distal main bronchus and/or sealed airway-esophageal fistula, that could not be covered by distal harms of Y stent. Thus, our hybrid stent had a sufficient length to cover all the stenosis in contrast to single stent, and it was readily available compared to custom-made stent. The length and size of each stent were chosen based on the patient airway anatomy after reviewing 3D CT scan findings. Silicone Y stents lack flexibility, and the bronchial limbs of these stents cannot 
be extended to fit in the tilting bronchi; SEMSs, however, are more flexible and can be placed to overlay the limbs of a $\mathrm{Y}$ stent to extend coverage into the distal bronchi with good stability. This hybrid stent adapts to bends and curvatures better than a single stent and can reestablish airways from the main carina to the distal main bronchi and seal the fistulas. The membrane of covered SEMSs can also prevent ingrowth of granulation tissue and reduces difficulty during stent removal. The uncovered sections at each side of the stent may promote epithelialization, improving mucociliary clearance and reducing stent migration. Hybrid stenting may therefore be an appropriate method to restore airway patency in patients with complicated malignant airways involving, for example, fistulas or long stenoses with varying diameters.

In our study, all patients had a tumor at the carina with complex airway stenoses involving carina and distal main bronchi or large fistula that involved the main carina and extended to the main bronchi. A single stent in these situations would not have been ideal for covering the entire length of stenosis or covering the fistula. Therefore, we used hybrid stent with the understanding that single silicone $\mathrm{Y}$ stent may not be effective in if (I) tumor at carina also involved one or bilateral main bronchi; (II) lesions were greater than $30 \mathrm{~mm}$ and invasion of a main bronchus; and (III) fistulas were located near carina or distal main bronchi.

Eighty-point six percent patients in the study experienced immediate relief of dyspnea after receiving hybrid stents, and fistula-related infections were controlled in all patients. The clinical outcomes of the patients in our study were similar to Matsumoto's study, which reported the combination stenting with silicone and metallic stents in the management of malignant airway stenosis in 7 patients. However, the study involved only 7 cases, and a single stent may solve the problem in the initial treatment in 3 of them whose second stent were inserted at 13-371 days. In our study, all the silicone Y stents and SEMSs were inserted within the same procedure. Meanwhile, the short-term effects of hybrid stents were similar to those observed in previous silicon Y stents studies and covered SEMSs $(3,4)$. And the mean duration of stent placement was close to the expected survival time of this specific patient population $(4,11)$. Conservative management of these patients is not an option, as it exposes them to life-threatening airway obstruction and infection (5). Previous studies have reported inconsistent findings regarding PS scores in patients with malignant stenosis and fistulas after stenting $(7,12)$. In this study, we found that airway stenosis and fistulas were associated with poor PS, and patients with a pre-stenting
PS score of greater than 3 showed significant improvement in their post-stenting PS scores. Some patients in this study were able to receive tumor-specific therapy after stenting. However, for patients who do not respond to these therapies, hybrid stenting can be used as an alternative palliative care method.

All the procedures were done under general anesthesia using both high frequency ventilation without mouth packing and conventional mechanical ventilation. These ventilation methods reduce air leakage, prevent hypercapnia, and reduce the length of surgery (13). McGrath et al. inserted SEMS under conscious sedation and using flexible bronchoscopy, however in our study group, this would not have been possible due to the requirement of a rigid bronchoscope for hybrid stent placement in complex lesions (14).

The technique used in our study is similar to those described in prior studies $(3,4,9)$. When inserting a stent, the distal end of the bronchoscope should reach the lesion's proximal aspect. Both the left and right main bronchi should be clearly identified to secure bronchial limbs into position. The pull-back technique is required when placing stents in patients with airway fistulas to avoid injuring these fistulas. Selecting a Y stent with an appropriate diameter aligned with the trachea and bronchi is vital; an oversized stent may cause injury and angulation. In patients with disease at tumor at carina, the distal bronchial limbs were fashioned into the uninvolved bronchi for a length of 10-15 $\mathrm{mm}$ to maintain the configuration at the carina and reduce migration. In patients with bronchial tumors, the bronchial limbs should not exceed $20 \mathrm{~mm}$ in length to prevent angulation. If the silicone $\mathrm{Y}$ stent could not completely cover the lesion on the main bronchi, SEMSs should be placed after of silicone stent's insertion.

The long-term safety of silicone stents placement has been well studied. The long-term implication of uncovered SEMS is controversial previously due to the high rate of complications. However, emerging evidences have suggested that covered SEMS could be safe for the majority of patients. And the complications are similar among two types of the stents in most conditions which included migration, granulation, diminished mucociliary clearance and patient intolerance. Previous studies have reported the complication rate of $16.1-40.9 \%$ in re-establishment of airway with Y stents and 31.3-44.4\% with SEMS (15-17). In this study, no major surgical complications occurred, and the most common complications on patient presentation were mild granulation ingrowth and secretion retention. 
No serious complications occurred in the 6 months following stent placement. This suggests that hybrid stenting is a safe and well-tolerated alternative treatment in the short-term management of malignant stenosis and fistulas. However, it should be noted that hybrid stents may increase secretion retention risk due to their large coverage area, and we recommend that patients administer aerosolized saline solution three to five times daily while hybrid stents are in place. In the current study, there were no metallic or silicone stents-related respiratory infections happened post-stenting. However, It has been reported that pneumonia, bronchial, cavitary pneumonia/lung abscess and intraluminal fungus ball were the most common types of stent-associated respiratory infection. And colonization with bacteria and fungi of the mucus layer is a common event associated with infection. Suggesting the need for establishing the definition and the diagnostic criteria for stent-associated respiratory infection. Hence, surveillance bronchoscopy within 4 to 6 weeks of stent placement may be useful for early detection of complications and their subsequent management, regardless of symptomatic status and indication for stent placement (18). There were several limitations to our study. First, this was a retrospective study that did not compare hybrid stents with other stenting methods, for example, single stenting. However, as the patients involved in this study suffered severe complicated airway stenosis with or without fistulas, we determined that single stenting was not an appropriate method to restore patency to these patients' airways. Secondly, there was no long-term follow-up in this study. The patients enrolled had terminal lung cancer with airway involvement and our goal was to investigate hybrid stenting as palliative treatment rather than curative treatment. It was not part of our study design to remove these stents. Third, the number of patient samples in this study is relatively small, and further study with large sample size is therefore required to explore the long-term efficacy and safety of hybrid stents.

In conclusion, we recommend the use of hybrid stents in the palliative treatment of patients with complex malignant airway stenosis and fistulas. The patients in our study experienced relief of symptoms related to stenosis and fistulas, which improved their quality of life with fewer complications.

\section{Acknowledgments}

The authors appreciate the academic support from AME Lung Cancer Collaborative Group.
Funding: This study was supported by the Clinical Innovation Research Program of Guangzhou Regenerative Medicine and Health Guangdong Laboratory (2018GZR0201002).

\section{Footnote}

Reporting Checklist: The authors have completed the STROBE reporting checklist. Available at http://dx.doi. org/10.21037/tlcr-21-353

Data Sharing Statement: Available at http://dx.doi. org/10.21037/tlcr-21-353

Conflicts of Interest: All authors have completed the ICMJE uniform disclosure form (available at http://dx.doi. org/10.21037/tlcr-21-353). SRD provides independent image analysis for hospital contracted clinical research trials programs for Merck, Pfizer, Bristol Mayer Squibb, Novartis, Roche, Polaris, Cascadian, Abbvie, Gradalis, Clinical Bay, Zai laboratories. Received honorarium from: Siemens and research grant from Lunit Inc, not related to work. Shi-Yue $\mathrm{Li}$ declared that he had received the Clinical Innovation Research Program of Guangzhou Regenerative Medicine and Health Guangdong Laboratory (2018GZR0201002), and that the funding source didn't play any role on the study. The other authors have no conflicts of interest to declare.

Ethical Statement: The authors are accountable for all aspects of the work in ensuring that questions related to the accuracy or integrity of any part of the work are appropriately investigated and resolved. This study was approved by the Ethics Committee of the First Affiliated Hospital of Guangzhou Medical University (Approval Number: 2018-16). All procedures performed in this study involving human participants were in accordance with the Declaration of Helsinki (as revised in 2013). Individual consent for this retrospective analysis was waived.

Open Access Statement: This is an Open Access article distributed in accordance with the Creative Commons Attribution-NonCommercial-NoDerivs 4.0 International License (CC BY-NC-ND 4.0), which permits the noncommercial replication and distribution of the article with the strict proviso that no changes or edits are made and the original work is properly cited (including links to both the formal publication through the relevant DOI and the license). 
See: https://creativecommons.org/licenses/by-nc-nd/4.0/.

\section{References}

1. Gompelmann D, Eberhardt R, Herth FJ. Advanced malignant lung disease: what the specialist can offer. Respiration 2011;82:111-23.

2. Bolliger CT, Probst R, Tschopp K, et al. Silicone stents in the management of inoperable tracheobronchial stenoses. Indications and limitations. Chest 1993;104:1653-9.

3. Miyazawa T, Yamakido M, Ikeda S, et al. Implantation of ultraflex nitinol stents in malignant tracheobronchial stenoses. Chest 2000;118:959-65.

4. Dutau H, Toutblanc B, Lamb C, et al. Use of the Dumon Y-stent in the management of malignant disease involving the carina: a retrospective review of 86 patients. Chest 2004;126:951-8.

5. Matsumoto K, Yamasaki N, Tsuchiya T, et al. Double stenting with silicone and metallic stents for malignant airway stenosis. Surg Today 2017;47:1027-35.

6. Kim J, Shin JH, Kim JH, et al. Metallic stent placement for the management of tracheal carina strictures and fistulas: technical and clinical outcomes. AJR Am J Roentgenol 2014;202:880-5

7. Furukawa K, Ishida J, Yamaguchi G, et al. The role of airway stent placement in the management of tracheobronchial stenosis caused by inoperable advanced lung cancer. Surg Today 2010;40:315-20.

8. Wang T, Zhang J, Qiu XJ, et al. Customized selfexpanding bare metal $\mathrm{Y}$ stents in the treatment of malignant carinal stenosis: a retrospective analysis. Ann Palliat Med 2021;10:4184-92.

9. Oki M, Saka H, Kitagawa C, et al. Silicone y-stent placement on the carina between bronchus to the right

Cite this article as: Chen Y, Zhou ZQ, Feng JX, Su ZQ, Zhong CH, Lu LY, Chen XB, Tang CL, Digumarthy SR, Fiorelli A, Natour E, Lococo F, Petrella F, Harris K, Nakada T, Zhong NS, Li SY. Hybrid stenting with silicone Y stents and metallic stents in the management of severe malignant airway stenosis and fistulas. Transl Lung Cancer Res 2021;10(5):22182228. doi: $10.21037 /$ tlcr-21-353 upper lobe and bronchus intermedius. Ann Thorac Surg 2009;87:971-4.

10. Su JM, Wu TC, Wu MF, et al. Management of malignant tracheobronchial stenoses with the use of airway stents. J Chin Med Assoc 2004;67:458-64.

11. Vonk-Noordegraaf A, Postmus PE, Sutedja TG. Tracheobronchial stenting in the terminal care of cancer patients with central airways obstruction. Chest 2001;120:1811-4.

12. Tsukioka T, Takahama M, Nakajima R, et al. Sequential stenting for extensive malignant airway stenosis. Ann Thorac Cardiovasc Surg 2015;21:114-8.

13. Petrella F, Borri A, Casiraghi M, et al. Operative rigid bronchoscopy: indications, basic techniques and results. Multimed Man Cardiothorac Surg 2014;2014:mmu006.

14. McGrath EE, Warriner D, Anderson P. The insertion of self expanding metal stents with flexible bronchoscopy under sedation for malignant tracheobronchial stenosis: a single-center retrospective analysis. Arch Bronconeumol 2012;48:43-8.

15. Bi Y, Li J, Yu Z, et al. Metallic small y stent placement at primary right carina for bronchial disease. BMC Pulm Med 2018;18:182.

16. Bi Y, Li J, Yu Z, et al. Multiple Bifurcated Covered SelfExpanding Metallic Stents for Complex Tracheobronchial Fistulas or Stenosis. Cardiovasc Intervent Radiol 2019;42:426-32.

17. Bi Y, Li J, Wu G, et al. A small bifurcated self-expanding metallic stent for malignant bronchial fistula or severe stenosis around the upper left carina. Acta Radiol 2020;61:613-9.

18. Lee HJ, Labaki W, Yu DH, et al. Airway stent complications: the role of follow-up bronchoscopy as a surveillance method. J Thorac Dis 2017;9:4651-9. 